\title{
Enhancing Yoga with Biofeedback
}

\author{
Erik Peper* \\ Department of Health Education, San Francisco State University, USA
}

Submission: July 24, 2017; Published: July 27, 2017

*Corresponding author: Erik Peper, Institute for Holistic Healing Studies/Department of Health Education, San Francisco State University, USA, Tel: 510-681-6301; Email: epeper@sfsu.edu

Keywords: Biofeedback; Yoga; Electromyography; Awareness; Respiration; Posture

\section{Introduction}

i. How can you demonstrate that yoga practices are beneficial?

ii. How do you know you are tightening the correct muscles or relaxing the muscle not involved in the movement when practicing asanas.

iii. How can you know that the person is mindful and not sleepy or worrying when meditating?

iv. How do you know the breathing pattern is correct when practicing pranayama?

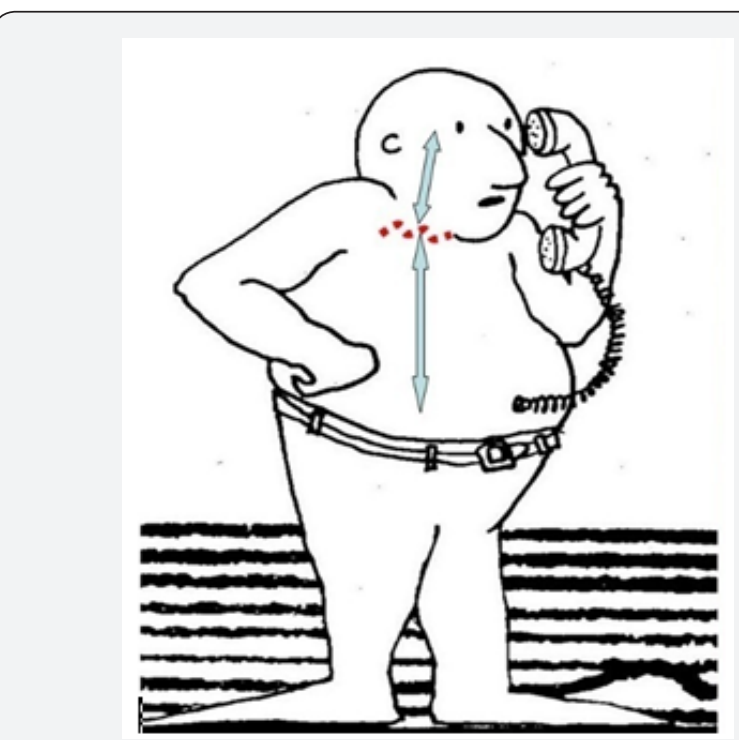

Figure 1: Biofeedback is a methodology by which the participant receives ongoing feedback of the physiological changes that are occurring within the body.

The obvious answer would be, ask the instructor or check in with the participant; however, it is often very challenging for the teacher or participant to know. Many participants think that they are muscularly relaxed while in fact there is ongoing covert muscle tension as measured by electromyography (EMG). Some participants after performing an asana, do not relax their muscles even though they report feeling relaxed. Similarly, some people practice specific pranayama breathing practice with the purpose of restoring the sympathetic/parasympathetic system; however, they may not be doing it correctly. Similarly, when meditating, a person may become sleepy or their attention wanders and is captured by worries, dreams, and concerns instead of being present with the mantra. These problems may be resolved by integrating bio- and neurofeedback with yoga instruction and practice. Biofeedback monitors the physiological signals produced by the body and displays them back to the person as shown in Figure 1 Reproduced with permission from Peper et al. [1].

With the appropriate biofeedback equipment, one can easily record muscle tension, temperature, blood flow and pulse from the finger, heart rate, respiration, sweating response, posture alignment, etc [2]. Neurofeedback records the brainwaves (electroencephalography) and can selectively feedback certain EEG patterns. In most cases participants are unaware of subtle physiological changes that can occur. However, when the physiological signals are displayed so that the person can see or hear the changes in their physiology they learn internal awareness that is associated with these physiological changes and learn mastery and control. Biofeedback and neuro feedback is a tool to make the invisible, visible; the unfelt, felt and the undocumented, documented. Biofeedback can be used to document that a purported yoga practice actually affects the psychophysiology. For example, in our research with the Japanese Yogi, Mr. Kawakami, who was bestowed the title "Yoga Samrat' by the Indian Yoga Culture Federation in 1983, we measured his 


\section{Journal of Yoga and Physiotherapy}

physiological responses while breathing at two breaths a minute as well as when he inserted non-sterilized skewers through his tongue [3-5]. The physiological recordings confirmed that his Oxygen saturation stayed normal while breathing two breaths per minute and that he did not trigger any physiological arousal during the skewer piercing. The electroencephalographic recordings showed that there was no response or registration of pain. A useful approach of using biofeedback with yoga instruction is to monitor muscle activity to measure whether the person is performing the movement appropriately. Often the person tightens the wrong muscles or performs with too much effort, or does not relax after performing. An example of recording muscle tension as shown in Figure 2.

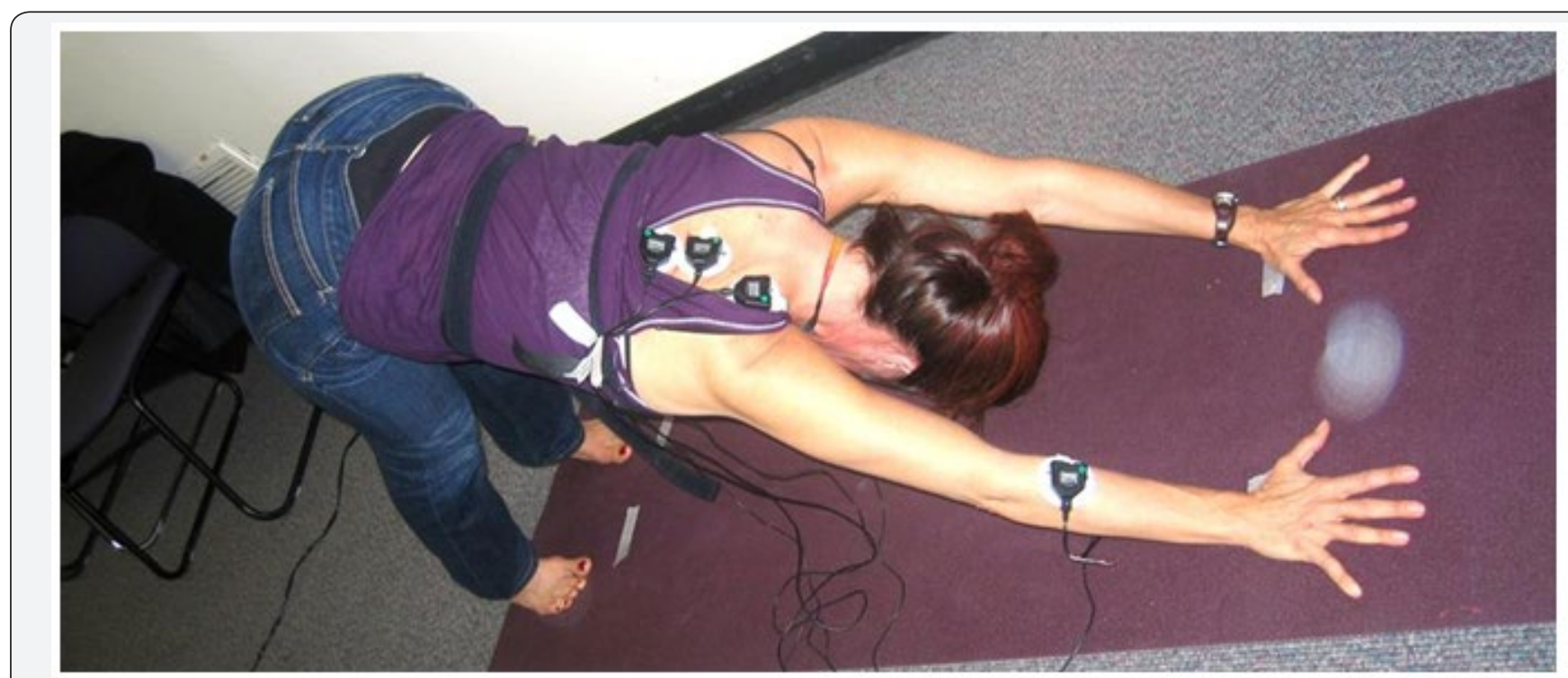

Figure 2: Recording the muscle tension with biograph infinity while performing an asana.

In our research it is clear that many people are unaware that they tighten muscles. Mcphetridge et al. [6] showed that when participants were asked to bend forward slowly to touch their toes and then hang relaxed in a forward fold, most participants reported that they were totally relaxed in their neck. In actuality, they were not relaxed as their neck muscles were still contracting as recorded by electromyography (EMG). After muscle biofeedback training, they all learned to let their neck muscles be totally relaxed in the hanging fold position as shown in Figure $3 \& 4$.

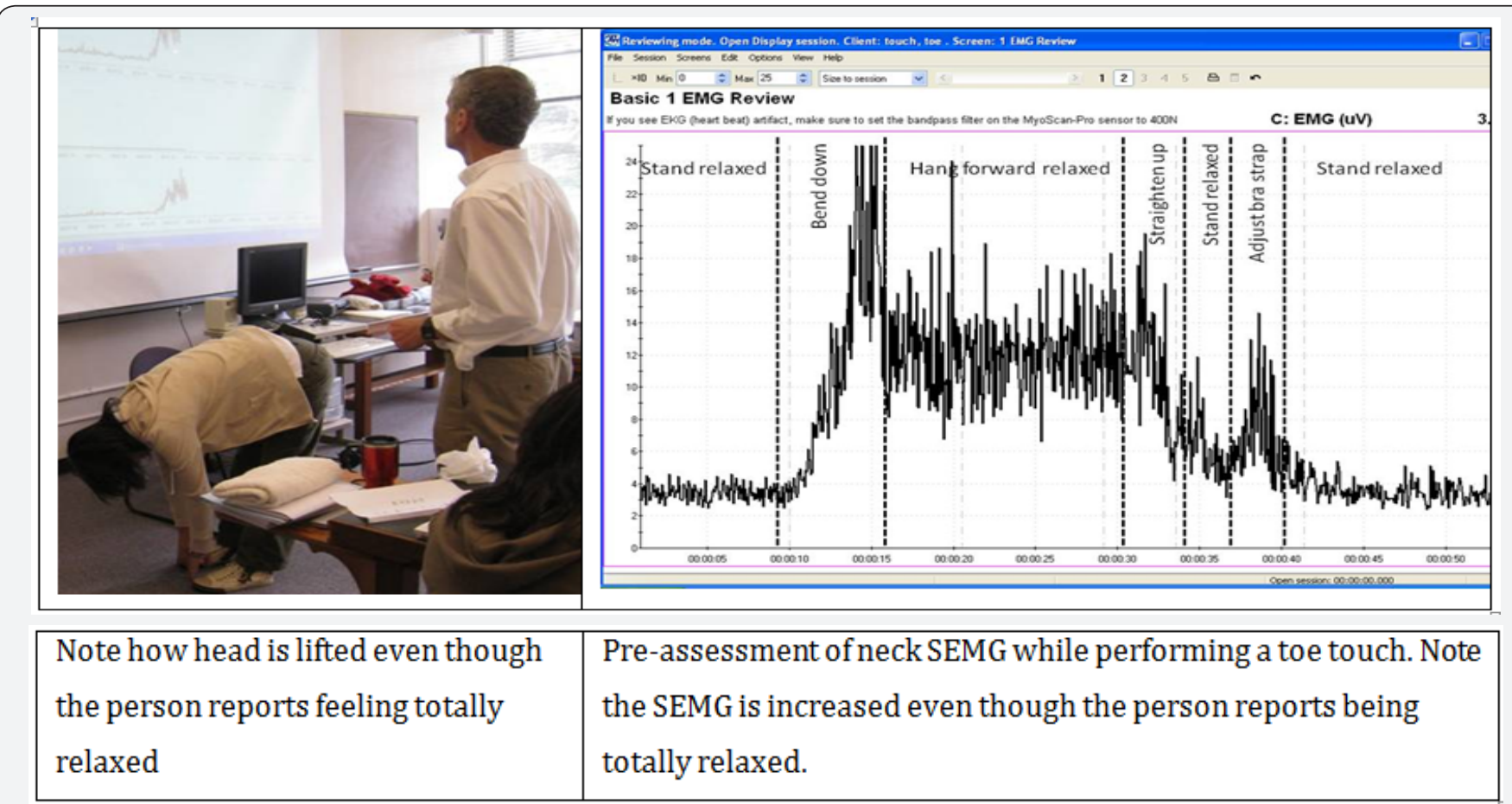

Figure 3: Initial assessment of neck SEMG while performing a toe touch [6]. 


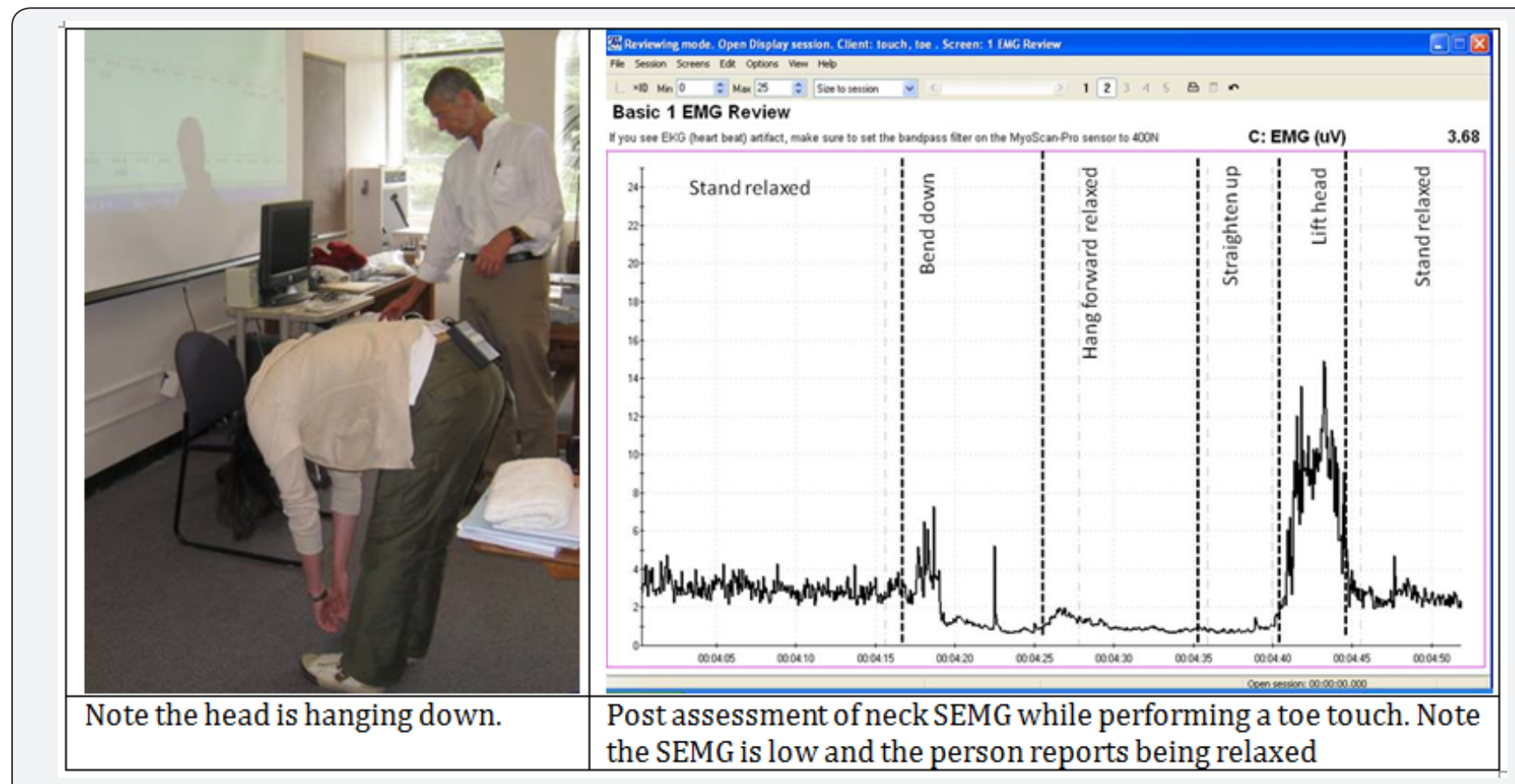

Figure 4: Toe touch after feedback training. The neck is now relaxed; however, the form is still not optimum [6].

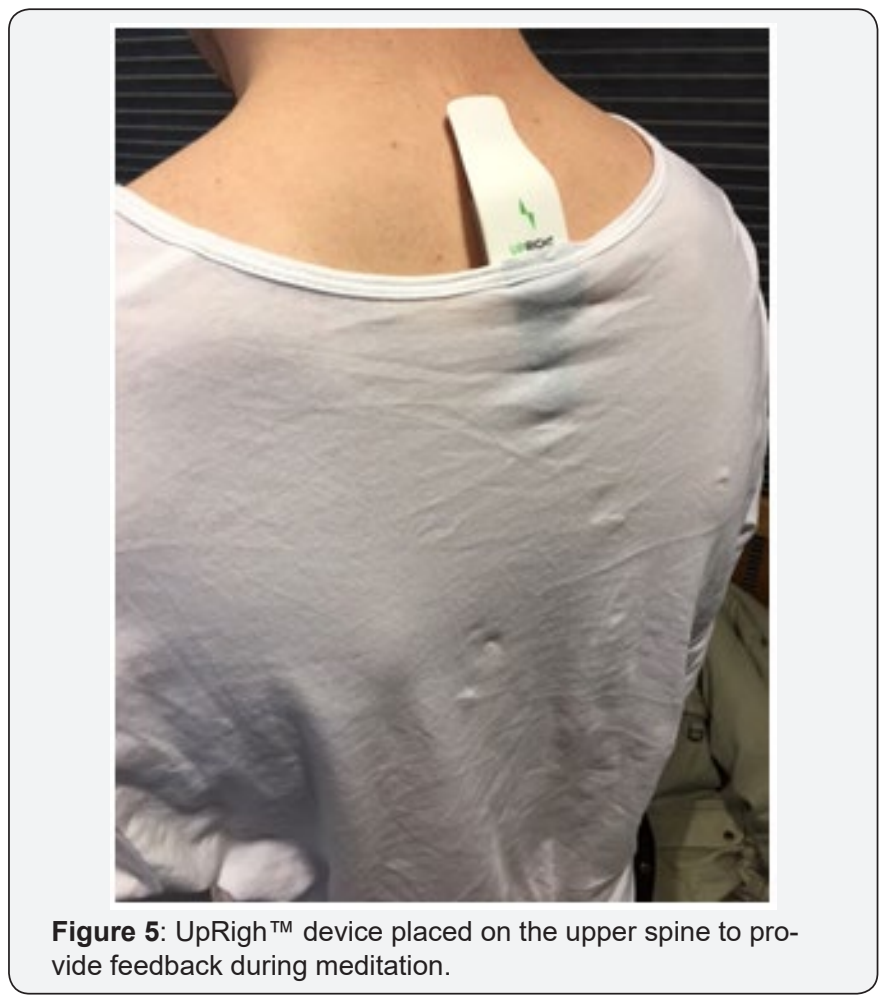

Thus, muscle feedback is a superb tool to integrate with teaching yoga so that participants can perform asanas with least amount of inappropriate tension and also can relax totally after having tightened the muscles. Biofeedback can similarly be used to monitor body posture during meditation. Often participants become sleepy or their attention drifts and gets captured by imagery or worries. When they become sleepy, they usually begin to slouch. This change in body position can be readily be monitored with a posture feedback device. The UpRight ${ }^{\mathrm{TM}}$ is a small sensor that is placed on the upper or lower spine and connects with Bluetooth to the cell phone. After calibration of erect and slouched positions, the device gives vibratory feedback each time the participant slouches and reminds the participant to come back to sitting upright as shown in Figure 5. Each time person slouches which often occurs when they become sleepy or loose meditative focus, the device provides feedback by vibrating.

Alternatively, thebrainwavespatterns(electroencephalography) could be monitored with neurofeedback and whenever the person drifts into sleep or becomes excessively aroused by worry, EEG feedback could remind the person to be let go and be centered. Finally, biofeedback can be used with pranayama practice. When a person is breathing approximately six breaths per minute heart rate variability can increase. This means that during inhalation heart rate increases and during exhalation heart rate decreases. When the person breathes so that the heart rate variability increases, it optimizes sympathetic/parasympathetic activity. There are now many wearable biofeedback devices that can accurately monitor heart rate variability and display the changes in heart rate as modulated by breathing.

\section{Conclusion}

Biofeedback is a useful strategy to enhance yoga practice as it makes the invisible visible. It allows the teacher and the student to become aware of the dysfunctional patterns that may be occurring beneath awareness. 


\section{References}

1. Peper E, Tylova H, Gibney KH, Harvey R, Combatalade D (2008) Biofeedback Mastery-An Experiential Teaching and Self-Training Manual. Association for Applied Psychophysiology \& Biofeedback, p. 438

2. Harvey E, Peper E (2011) I thought I was relaxed: The use of SEMG biofeedback for training awareness and control. In: WA Edmonds, G Tenenbaum (Eds.), Case studies in applied psychophysiology: Neurofeedback and biofeedback treatments for advances in human performance. West Sussex, Wiley-Blackwell, UK, pp. 144-159.

3. Arambula P, Peper E, Kawakami M, Gibney KH (2001) The physiological correlates of Kundalini Yoga meditation: a study of a yoga master. Appl Psychophysiol Biofeedback 26(2): 147-153.

This work is licensed under Creative Commons Attribution 4.0 License

DOI: 10.19080/JYP.2017.02.555584
4. Peper E, Kawakami M, Sata M, Franklin Y, Gibney KH, et al. (2005a) Two breaths per minute yogic breathing. In: Kawakami M (Ed.), The Theses of Mitsumasa Kawakami II: The Theory of Yoga-Based Good Health. Japan, pp. 483-493.

5. Peper E, Kawakami M, Sata M, Wilson VS (2005b) The physiological correlates of body piercing by a yoga master: Control of pain and bleeding. Subtle Energies \& Energy Medicine Journal 14(3): 223-237.

6. Mcphetridge J, Thorne E, Peper E, Harvey R (2011) SEMG for training awareness and muscle relaxation during toe touching. Paper presented at the $15^{\text {th }}$ Annual Meeting of the Biofeedback Foundation of Europe. Germany, pp. 22-26.

Your next submission with Juniper Publishers
will reach you the below assets
- Quality Editorial service
- Swift Peer Review
- Reprints availability
- E-prints Service
- Manuscript Podcast for convenient understanding
- Global attainment for your research
- Manuscript accessibility in different formats
( Pdf, E-pub, Full Text, Audio)
- Unceasing customer service
Track the below URL for one-step submission
https://juniperpublishers.com/online-submission.php

